\title{
Putting Business Students in the Shoes of an Executive: An Applied Learning Approach to Developing Decision Making Skills
}

\author{
Jeanny Liu, PhD \\ Associate Professor, College of Business and Public Administration \\ University of La Verne \\ Deborah Olson, PhD \\ Associate Professor, College of Business and Public Administration \\ University of La Verne
}

Students often struggle with how to translate textbook concepts into real-world applications that allow them to personally experience the importance of these concepts. This is an ongoing challenge within all disciplines in higher education. To address this, faculty design their courses using methods beyond traditional classroom lectures to facilitate and reinforce student learning. The authors believe that students who are given hands-on problem-solving opportunities are more likely to retain such knowledge and apply it outside the classroom, in the workplace, volunteer activities, and other personal pursuits. In an attempt to engage students and provide them with meaningful opportunities to apply course concepts, the authors have initiated a number of experiential learning methods in the classroom. Since fall of 2008, elements of problem-based learning were integrated in the authors' business courses. Specifically, real-world consulting projects were introduced into their classrooms. This paper focuses on the authors' experiences implementing problem-based learning processes and practical project assignments that actively engage students in the learning process. The experiences and the feedback gathered from students and executives who participated in the "realworld" project are reported in this paper.

Experiential Learning Theory (ELT) is based on the work of Dewey, Lewin, and Piaget (Kolb, 1984). This approach is an established, integrative, holistic learning process that combines experience, perception, cognition, and behavioral learning approaches that optimize student learning and retention. Kolb and Kolb (2005) define experiential learning as a process that relies primarily on creating an environment in which students have direct experiences using concepts and theories presented in class. The goals of adopting experiential learning in the classroom include engaging students at a higher level of cognitive complexity, involving students in an active learning environment, demonstrating the application of theories in real-world situations, and developing students' ability to make business decisions that are based on analytical approaches.

Experiential learning has become a significant educational pedagogy that has influenced the teaching and learning process for faculty and instructors at many educational

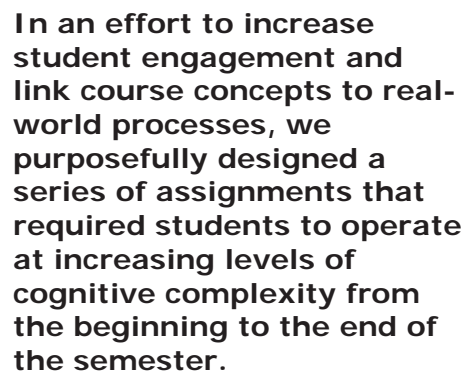

institutions and in and across disciplines (Daly, 2001). Common forms of experiential learning include case studies, computer simulations, service learning projects, travel study courses, internships, and real-life consulting projects. Instructors who wish to pursue experiential learning pedagogies can avail themselves of a wide range of teaching methods and approaches. Each method has distinct advantages and disadvantages. These approaches can be ranked on a continuum representing increasing levels of cognitive complexity and linkages to real-world outcomes and processes. Table 1 below summarizes various experiential 
learning exercises based on an increasing level of cognitive complexity. At the lower levels of complexity, students learn the concepts and apply those to scenarios generated by the professor or other experts in the field. The lower levels include assignments such as computer simulations, role playing, and case studies. At this level, students do not experience any real-world consequences of their decisions or actions.

Table 1: A Comparison of Experiential Learning Exercises by Level of Cognitive Complexity

\begin{tabular}{|c|c|c|c|c|c|c|}
\hline $\begin{array}{l}\text { Types of } \\
\text { Experiential } \\
\text { Learning } \\
\text { Exercises }\end{array}$ & $\begin{array}{l}\text { Cognitive } \\
\text { Complexity }\end{array}$ & $\begin{array}{l}\text { Real } \\
\text { Decision } \\
\text { Making } \\
\text { Skills }\end{array}$ & $\begin{array}{l}\text { Real- } \\
\text { World } \\
\text { Contact }\end{array}$ & $\begin{array}{c}\text { Real } \\
\text { Consequences }\end{array}$ & $\begin{array}{l}\text { Group } \\
\text { Based }\end{array}$ & $\begin{array}{c}\text { Real } \\
\text { Feedback }\end{array}$ \\
\hline $\begin{array}{l}\text { Computer } \\
\text { Simulation } \\
\text { Role Playing } \\
\text { Case Study }\end{array}$ & $\begin{array}{l}\text { Low- } \\
\text { Moderate }\end{array}$ & $\begin{array}{l}\text { Low to } \\
\text { Medium }\end{array}$ & No & No & Yes & No \\
\hline $\begin{array}{l}\text { Student } \\
\text { Operated } \\
\text { Business } \\
\text { Client } \\
\text { Consulting } \\
\text { Project }\end{array}$ & $\begin{array}{c}\text { Moderate- } \\
\text { High }\end{array}$ & $\begin{array}{l}\text { Medium to } \\
\text { High }\end{array}$ & Yes & Yes & Yes & Yes \\
\hline $\begin{array}{l}\text { Set up \& Run a } \\
\text { Mock Business } \\
\text { Internship }\end{array}$ & High & High & Yes & Yes & Yes & Yes \\
\hline
\end{tabular}

The approach presented in this paper focuses on processes to engage students using the higher levels of cognitive complexity. This method aims to design a learning experience that engages students at a higher cognitive complexity and creates opportunities for students to work in teams and interact with business leaders to make decisions that have real-world consequences. Specifically, the approach described in this paper focused on how to put students in the shoes of executives by integrating a consulting project into the learning design of the course. This approach prepares students to think critically by giving them the opportunity to see the challenges that executives face when they have to make important decisions that will impact (it is hoped positively) the growth and viability of their businesses. This experience allows students to develop greater insight into the challenges they will face as they enter the workplace after college. Having a deep understanding of the complexity of the markets and the workplace will help students make more astute personal decisions about their career options and will increase the value they bring to the organizations for which they choose to work.

\section{Adopting a Real-Client Consulting Project}

Researchers have emphasized the need for a real-life project selection and evaluation (Lopez \& Lee, 2005). To create an effective learning process for the students, the organizational leaders who are to be selected for the students to work with should be carefully evaluated to ensure that they are willing to assist students in learning, as well as value the proposals that the students share with them to 
improve their organization. Lopez and Lee (2005) suggest five principles for selecting workable client-based projects: (1) select clients with care, (2) design projects of varying scope, (3) invest in advance planning, (4) manage and set high expectations, and (5) provide periodic and productive feedback.

In applying Lopez and Lee's (2005) principles, we found it to be more efficient to use one common client across multiple related courses. This allowed us to source and prepare for a high quality client. In addition, the students knew they were competing with other classes (i.e., two undergraduate classes and one graduate level class), and this raised the overall quality of the students' work.

For their consulting client, we selected Massage U, Inc., founded in 2006 by Paul Kleiman, a physical therapist. Massage U's main product, the Roleo Massager, is designed to help people who suffer from carpal tunnel and other hand/forearm injuries. Paul and his two business partners (a marketing director for Neutrogena and a medical doctor who specializes in repetitive stress injuries) wanted help in bringing their product concept to market. Like many early-stage companies, Massage $U$ had limited resources and spent most of its start-up capital developing the product. To take their business to the next level, the partners needed a better understanding of their market and a well-designed overall strategy. This was the value the students could offer to the leaders of Massage U. The project for the students was to create an integrated marketing plan to increase awareness in their target markets and deliver a go-to-market plan in a cost efficient manner.

Table 2 provides a summary of the consulting project assignment that was given to the students. The students were asked to interact with Massage U's founders and assess the current marketing practices, as well as make recommendations at the end of the term.

Table 2: Consulting Project Description

\section{Client Consulting Project}

You and your group will create a marketing plan for Massage U, Inc. You will compete with other teams to generate the best marketing program. The objective of the project is to investigate the issues and challenges of the Roleo Therapeutic Massager product and generate a marketing plan to help the business to increase short-term sales and long-term strategic actions. This project consists of two parts: a written part of the project and a presentation component. The basic outline of your presentation is as follows:

Part I: Current Company and Industry Situation and Challenges

- Company Information

- Industry Information

- Identify Current Competition in the Market

- Identify Current Target Market that the business is serving

- Identify the Risks and Challenges of continuing the business without any changes

Part II: Assess Future or Potential Demand

- $\quad$ Potential Future Demand in the Market (e.g., Consumer Behavior Changes)

- Consumers' Needs or Taste Preference for this Product/Service (e.g., Types of substitutable therapies)

- Discuss Segmentation Variables (e.g., Income, Population, Lifestyle, Usage Rate, etc.)

- $\quad$ Describe the Chosen Target Market(s) 
- $\quad$ Discuss Other Variables that would fit the chosen target market and would make the product a success (e.g., consumption statistics, macroeconomic trends, microeconomic trends, etc.)

Part III: Recommendation and Marketing Program

- Proposed Product Offering/Service Offering Information

- Proposed Value Proposition

- $\quad$ Proposed Pricing Strategy

- $\quad$ Proposed Promotion Strategy

- $\quad$ Proposed Distribution Strategy

Students were assigned to groups in order to work together to develop an integrated approach that addressed the founders' needs. The students' groups met with the founders and asked questions to gather specific data relevant to the problems that faced Massage U's market. Using the data they gathered and the concepts they learned earlier in the semester, the students conducted systematic research on the organization and its competitive environment.

Multiple sections of the same business marketing course were involved simultaneously in this client consulting assignment. Having multiple classes of students working on the same client not only provided different approaches and perspectives for the client to consider, but also interjected a "competitive spirit" among the student teams that pushed them to expand their approach and raised the quality of their work. The following describes briefly the three classes that participated in this learning process and the learning objectives of each course.

Marketing Principles (Bus 360) is a core course for the bachelor of business administration students and an elective for accounting and economics students. This is the first marketing class for business majors. The course goals are to (a) develop an awareness of current practice and trends employed and affecting the practice of moving the product from the producer to the customer/consumer; (b) demonstrate the ability to create a strategic marketing plan; (c) develop insight into the processes for developing efficient strategies for the marketing of goods and services; (d) develop the ability to assess the status of a marketing effort and to employ marketing theory to improve its effectiveness; (e) instill the thought that modern marketing is one of global consideration and that a marketing effort must be designed and maintained as one operating in an arena of global competition; and (f) provide an overview of the current technology influences on the traditional marketing environment and the management of the marketing mix, including product planning, pricing, promotion, and channel distribution. The class that participated in this study is composed of 15 traditional undergraduate students with a $40 \%$ mix of adult students. Students are mainly sophomores and juniors but not necessarily with an emphasis in Marketing. The class meets once a week for 15 weeks.

Marketing Management (Bus 461) is a required course for students seeking a marketing concentration in the business administration program. This is the upper division business elective course for undergraduate students. The course is intended to deepen students' understanding in marketing, and a business principles course is a prerequisite for this course. Students came to the course with a higher level understanding of marketing concepts and knowledge, and had already taken Marketing Principles (Bus 360). The course goals are (a) to develop in the student a deeper understanding of the critical role marketing plays in the progressive firm's strategic and tactical operations; (b) to enhance the student's understanding of the marketing management function in consumer product, industrial, nonprofit, and service; (c) to assist the student in building the skills and intellectual processes 
necessary to formulate successful marketing strategies; (d) to enhance the student's understanding of current practice with respect to marketing, the global nature of marketing, and the interdisciplinary skills required of today's modern executive; and (e) to enhance students' critical thinking and reasoning skills in the development and preparation of marketing plans and programs used by for-profit firms, public sector organizations, service businesses, and nonprofit organizations. The class that participated in this study is composed of ten traditional undergraduate students. Students are mainly juniors and seniors with little variation in age and experience. Many of them came from a retail background and currently worked full-time or part-time in retail. Class meets three times a week for 15 weeks.

Business Marketing (Bus 500F) This is a foundation course for MBA students who either have never taken a marketing course or have taken a slightly different business course in a foreign country and need the credits before entering the MBA program. This course is designed for those preparing to enter the graduate degree program but lacking either the academic background or equivalent experience in the marketing discipline necessary to participate successfully in courses leading to a degree. The course objectives are to (a) develop an awareness of current practice and trends employed and affecting the practice of moving the product from the producer to the customer/consumer; (b) demonstrate the ability to create a strategic marketing plan; (c) develop insight into the processes for developing efficient strategies for the marketing of goods and services; (d) develop the ability to assess the status of a marketing effort and to employ marketing theory to improve its effectiveness; (e) instill the thought that modern marketing is one of global consideration and that a marketing effort must be designed and maintained as one operating in an arena of global competition; and ( $f$ ) provide an overview of the current technology influences on the traditional marketing environment and the management of the marketing mix including product planning, pricing, promotion, and channel distribution. The class that participated in this study is composed of 27 pre-MBA students. Students came to the course with very little marketing knowledge but with some work experience. Approximately half of the class is English speaking adult students, and the other half are non-English speaking international students. The class meets once a week for ten weeks.

\section{Preparing the Students Prior to Presentation}

There are several approaches that an instructor may wish to employ while adopting a consulting project, none of which are mutually exclusive. It is recommended that, regardless of the specific methodology, students be exposed to some material related to the project. As echoed by Lopez and Lee (2005), client projects are doable, but the process requires a considerable amount of time commitment and planning. The authors suggest integrating the project as a final semester project. The project could easily fit within a four hour class block that meets once a week over the course of a 10 or 15 week period. In the consulting project described in this paper, the authors dedicated the last hour of each class session specifically to allow student teams to work together on the project.

In an effort to increase student engagement and link course concepts to real-world processes, we purposefully designed a series of assignments that required students to operate at increasing levels of cognitive complexity from the beginning to the end of the semester. When designing the assignments, we implemented a learn-by-doing applied learning process. Specifically, at the beginning of the semester, students were given carefully selected case studies that focus on businesses-to-consumers and small group exercises to prepare the students with baseline ability to apply marketing concepts before engaging the Massage $U$ founders. The professor led full class discussions on the key concepts and provided feedback on the quality of the student's analyses and approach to the 
cases and small group exercises. Once the concepts were understood, the professor introduced the client consulting challenge, thereby easing the students into interacting with real-world executives and preparing the students to be successful. Different tools and approaches that were used to facilitate learning for the students in the design of this project are summarized below.

Weekly Project Discussions and Assignments. One method to help students stay focused and involved in the project is to establish specific weekly milestones. To help

In an effort to increase student engagement and link course concepts to realworld processes, we purposefully designed a series of assignments that required students to operate at increasing levels of cognitive complexity from the beginning to the end of the semester. students meet deadlines and experience success in the course, a series of weekly assignments that are linked to course content and are central to achieving the objectives of the consulting project have been added to the overall course design. Each assignment is carefully designed to help students understand and apply theoretical concepts covered in class directly to the consulting project. The weekly cases and assignments were established to facilitate the students' development so that they would be prepared for the delivery of the final marketing plan and the presentation to the Massage $U$ business leaders at the end of the semester. Table 3 provides the list of weekly assignments completed by students.

\section{Table 3: Weekly Assignments Linked with Course Concepts}

Assignment for Discussion on Organization and Strategic Planning

- $\quad$ Conduct a SWOT analysis for Massage $U$, Inc., ie discuss its strengths, weaknesses, potential opportunities, and threats facing the company.

- Discuss the competitive environment and define the competitors of Massage U, Inc.

- Using a table format, compare the strengths and weaknesses of its competitors.

- $\quad$ Select which competitors to compete with or avoid and provide justifications.

- Post your responses on blackboard with appropriate references and citations.

Assignment for Discussion on Environmental Scanning

- $\quad$ Prepare a Marketing Environmental Analysis for Massage U, Inc. Conduct library research and evaluate the five environmental factors that are happening and relevant in the industry.

- $\quad$ Post your responses on blackboard with appropriate references (if any) and citations.

Assignment for Discussion on Consumer Behavior

- Determine the buying process of the user/client of Massage $U$, Inc

- How do/should consumers hear about the product?

- What needs do consumers have?

- What values do consumers desire from such a product? (Define the key drivers for this type of product/service)

- Who are the influencers and who would have influence over their decisions?

- Are there any substitute products?

- Describe (if any) potential post-purchase behavior.

- Post your responses on blackboard with appropriate references and citations. 
- Identify potential markets and segments for Massage $U$, Inc

- $\quad$ Select the most attractive target market(s) for the company and provide justifications with supporting evidence

- Create samples of perceptual maps using key satisfaction variables

- $\quad$ Post your responses on blackboard with appropriate references (if any) and citations.

Assignment for Discussion on Product and the Product Life Cycle

- Discuss whether there is a clear and distinct difference between Massage $U$, Inc. and its competition.

- If so, what are the few distinct differences that make Massage U's product unique or more desirable?

- $\quad$ Evaluate the product life cycle and its value offerings.

- What type of intangible attributes can Massage U, Inc. provide to differentiate itself in the industry?

- What type of value(s) should they capture for a more need driven model?

- Post your responses on blackboard with appropriate references (if any) and citations.

Assignment for Discussion on Price and Price Setting

- How would you describe Massage U's price positioning strategy?

- How does it relate to the 5 C's affecting the pricing structure? (For example: How does Massage U's current price structure compare to its competitors', relate to its customers, increase value through channel members, etc.)

- What type of price strategies can be applied toward a short-term effect in order to stimulate demand?

- What type of price strategies can be utilized in building long term perceived value for its targeted market segments?

- $\quad$ Post your responses on blackboard with appropriate references (if any) and citations.

\section{Wikis used to facilitate communication and successful project completion.}

After each weekly assignment, students are asked to transfer their group discussions and personal reflections in written form to a wiki page that is only visible to members within the team and the instructor. The instructor's role is one of a facilitator and helps to provide feedback to students to help them stay focused on the key issues. A wiki page can help the instructor to facilitate students' thoughts and ideas into written form after each group discussion.

To set up a wiki page, instructors can visit the content area through course management systems (i.e., Blackboard) and create a wiki page. For example, Blackboard allows instructors to choose and limit selected members who can access, view, and edit the wiki page. Similar to a white canvas, a wiki is a social media tool offering a blank web space that is available for students to collaborate on one document collectively. Students can co-create documents, share thoughts, reflect, upload images, give links to references, and allocate tasks to complete the project in one central area. This is a useful tool for students to effectively communicate virtually with each other without having to be bound by physical location or to deal with the issues of finding a common time to meet face to face. It also benefits instructors to facilitate discussions and monitor student progress. If, however, a wiki page is not available, Google offers a free discussion platform that utilizes a 
similar idea. Rather than a blank web space, Google groups or sites can be set up free of charge. In addition, the platform can be utilized to facilitate chats within groups and communications with outside people, mainly the business executives. For the past couple of years, the authors have found it useful in setting up a discussion area that links students to business executives via a discussion forum of this type. Based on the feedback from the executives, the discussion forum is an important tool that facilitates effective communications with the students.

Exam Questions for Individual Assessment. The instructor can also use concerns and questions about the project that arise each week to write specific exam questions that directly assess the individual student's ability to link the course concepts to the consulting project. For example, based on the Massage U's project, Table 4 shows a list of questions that were given in the form of a mini-midterm to assess individual student performance.

Table 4: Exam Questions to Assess I ndividual Student Performance

\begin{tabular}{|c|c|c|c|}
\hline $\begin{array}{l}\text { SAMPLE COURSE } \\
\text { OBIECTIVES }\end{array}$ & LEARNI NG & $\begin{array}{l}\text { EXAM QUESTIONS } \\
\text { LEARNING OBIECTIVES }\end{array}$ & MEET \\
\hline
\end{tabular}

Strategic market and product analysis

- $\quad$ product positioning

- $\quad$ product differentiation

- consumer value,

- target market identification
- Describe the industry that Massage $\mathrm{U}$ competes in. (Attach 3 credible articles/sources and correctly cite references at the end of the paper according to the APA format)

- $\quad$ Discuss the most important players (3-5) in the market and analyze their strategy and position in the market using a BCG Matrix (include Massage $U$ in the Matrix).

- If you were the deciding manager how would you have positioned the business? Create a perceptual map against other alike competitors. Explain where Massage $U$ is and where you would like to see it moving forward.

- Identify the key satisfaction factors for the shoppers of Massage $U$. Explain why.
Marketing plan and market strategy

- $\quad$ Strategic analysis and decision making

- $\quad$ Strategic capability analysis

- Marketing Management function

- Marketing strategy and integration with corporate strategy
Describe the key problems confronting Massage $U$ and make ONE recommendation for the company on the most important problem. Identify which key issue should be addressed and suggest an approach to solving the problem. What decisions need to be made by the upper management? Avoid any ambiguous recommendation and generate possible actionable strategies. Please be as specific and detailed as possible. (Follow the guidelines similar to the case writing below.) 
- WHY do you recommend it (support using theoretical framework)?

- HOW will it be implemented (be specific)?

- WHAT and which marketing strategy will be used?

- HOW much TIME, MONEY, and WHAT will it take to implement the strategy?

- JUSTIFY and PROVIDE SUPPORTING MATERIAL in the appendix why this solution is the best option through a logical argument supported by research.

These exam questions are framed to reflect and reinforce the required objectives to meet student learning outcomes for the course. The example midterm question shows how students are challenged to integrate course concepts (e.g., SWOT analysis, Boston Consulting Group matrix) and relate them to their project. This is an important step to help students to bring more clarity to their thoughts and frame their ideas regarding how to apply the concepts.

Case Study Method and Analyses. In addition to the consulting project, a series of case studies can be assigned to prepare students to think critically and strategically about significant business challenges that leaders face and need to address. These case studies would need to be carefully selected. We recommend beginning with short, less complicated cases and building toward more complex situations that require more sophisticated integration of analysis, course concepts, and creativity over the course of the semester. The traditional case study pedagogy has been commonly used in graduate programs (Forman, 2006). The authors found it useful to adopt the case study method even at the undergraduate level. An example of a valuable resource is the book Marketing Mistakes and Successes by Robert Hartley. This case book is easy to read and clearly structured, with insightful questions and debate exercises that point out the salient facts for each case. Students of varying ages and work experiences are able to grasp the concepts very quickly. Additionally, instructors can choose among cases that are relevant to the consulting project to establish basic concepts, develop awareness, spark interest, encourage dialogue, and expand the student's knowledge of the industry. These case studies are an important part of the design to build understanding and knowledge regarding the issues that executives confront in their business and that impact the marketing decisions and investments that business leaders make regularly.

Developing and Presenting Recommendations. At the end of the semester, a presentation meeting was scheduled with the business executives for students from all classes to come together to present their recommendations. The entire presentation process could range from two to four hours, depending upon the number of student groups that are presenting. In the example described in this paper, each team was given a maximum of 15 to 25 minutes to present their analyses and recommendations followed by a 5-minute question and answer session. During this meeting, the role of the executives was to evaluate, ask questions, and provide immediate feedback on the soundness of each plan. The feedback from the business executives was often perceived by the students as the most important factor that contributed to their growth, both academically and professionally. 


\section{The Consulting Project: Smaller is Better}

In the business schools, most professors have sought to adopt cases from Fortune 500 companies. However, based on our experience adopting client projects, we have found that small businesses provide an ideal venue for a class project. Small business executives are great candidates because of their willingness to devote more time to work with students and gain value from their innovative and thoughtful recommendations. We have found that, when carefully selected, leaders of small businesses are zealous in providing students with practical and detailed information, engaging students on discussion boards and in group chats, and giving frequent and timely feedback. In return, students are more likely to provide valuable and well-thought-out contributions to the success of the business. Often, small business leaders struggle with limited resources and sometimes lack formal business training. Additionally, many executives leading small businesses are able to quickly implement the suggestions they receive from the students. The impacts of the changes they make are often directly measurable and immediate. The authors have found that the leaders who have participated in this partnership are willing to provide students with status updates clearly describing the impact of their recommendations on market growth and profits.

Finding an appropriate business case to adopt can be a challenging task. Here are some resources that instructors can consider when searching for viable client projects.

- Select from a pool of personal contacts, professional organizations, friends, acquaintances

- Inquire about local interested businesses for potential on-site opportunities

- Inquire of interested individuals from present or past students

- Contact the University/School business advisory board for potential projects

- Create posting in Linkedln profile or Facebook, or School WebPage

\section{Facilitating Student Development}

Using a consulting project facilitates student development beyond assisting them in understanding the concepts related to the course objectives for the class. For example, the ability to ask clear and meaningful questions is a real-world skill that can be developed and refined during this type of real-world project assignment. To be effective when interacting with the leaders, the students prepared for the meetings with the executives by developing a list of questions to help them fully understand the business. To establish credibility with the leaders, students needed to do the necessary research about the organization before the meetings so that they did not "waste time" asking general questions to gather information that was available on their website or in other printed format. Instead, students asked clearly articulated questions that encouraged the executive to share specific nuances and complex issues that directly impacted the success of their business and perceptions of their product. It was through understanding the complexities of the issues and engaging in a meaningful dialogue about the organizational challenges that the students were able to see the world through the executives' eyes and understand the issues they faced daily.

In a traditional classroom lecture, the professor reviews concepts related to strengths, weaknesses, opportunities, and threats (SWOT) that the organizational leaders need to address. Having understood the concepts and process, students then complete a SWOT analysis of an organizational case that is in their text or is presented by the professor. In a traditional SWOT analysis, students need to answer questions such as "What are the strengths in terms of products and services that your company offers, relative to the competition in your markets?" However, in this consulting project context, the students need to probe for additional details about the strengths, weaknesses, opportunities, and threats, since they are not "neatly presented" in a written case that the students are reading in their texts. Students in this class who are interviewing the leader as part of their consulting project need to

InSight: A J ournal of Scholarly Teaching 
also ask a series of follow-up questions; to develop a meaningful marketing plan, they must understand the unique challenges faced by the small business leader. For example, their questions are formulated as follows:

- How have the changing demographics in Southern California impacted the design of products you have developed? Have you gathered data on changing customer preferences? How have you used the data you gathered to change, improve, or alter your product design?

- Have you done any trials or experiments for measuring the effectiveness of Roleo in alleviating pain observed in patients or customers? How do you currently position Roleo in comparison to other therapeutic massagers?

- Given that your products are 'discretionary purchases', how have you changed your marketing process to keep your current customers? What actions have you taken to attract new customers?

- Traditionally you have used local suppliers for the materials to manufacture your product; what impact has competition from offshore manufacturers had on your product position and customer base?

As with all experiential learning processes, professors need to encourage students to ask and reflect on questions such as "Did this class expand my ability to think about marketing processes and organizational decisions in a new or different way?" In the example described in this paper, each class session created new ways to integrate the marketing concepts with the real- world challenges that leaders face every day in their businesses. Faculty need to ensure that students are regularly reflecting on their learning and integrating the information discussed during each class session. This can be done through use of reflective learning summaries written each week and/or blogs on which students can share their knowledge and perspectives with each other. The faculty can use these reflective tools to identify gaps in students' understanding, and have as well students share their perspectives and insights with the class. Thus peer learning occurs, encouraged by the instructor. This is consistent with John Dewey's (1938) assertion that we learn not just by having experiences, but also by reflecting on those experiences and identifying what we have learned.

The design of the consulting project in this class ensures that students have the opportunity to meet with small business owners and talk with them in detail about their business. The development and learning that students experienced went beyond the integration of course concepts. The contribution to students'

Faculty need to ensure that students are regularly reflecting on their learning and integrating the information discussed during each class session.

development included the following:

- The ability to obtain information directly from business leaders enabled students to understand that in real-world settings, data is not neatly summarized; often, new information emerges that needs to be integrated and addressed by the leaders who are running the business. This reinforced the understanding that business leaders face problems that are multidimensional and constantly changing. This shows that decisions made in the past impact the business decisions made to address current opportunities and challenges.

- Students received feedback from the business leaders in "real time," so that the students knew which ideas were meaningful and could be used in the business and which ideas were too "conceptual" and did not offer added value from the business leaders' perspective.

- The business leaders offered students feedback on the quality of their marketing plans and the professionalism of their presentations. This offers students a unique developmental opportunity to change, improve, and adapt their presentation skills and ability to articulate ideas and concepts; when they begin interviewing for jobs, they can then reflect on what they learned from the leaders' feedback in this consulting project. 
- Students are able to see how the course material fits contextually into the real world. For example, in the Massage $U$ consulting project, students are challenged to link marketing to strategy, finance, and sales in the process of developing their recommendations.

The interaction with the executive in the consulting project is another dimension of learning that is created through this type of experiential course design and that can make a significant impact on student development and growth. From interacting with the business executives, students gain a greater sense of careerrelevant skills and professionalism. Skills that students have an opportunity to develop include (1) business acumen through expanding their understanding of the challenges and issues from the business leader's perspective; (2) self-confidence through the process of engaging in discussions with the business leaders and making presentations to them; and 3) interpersonal and communication skills through working with other students on the consulting project team, as well as through meaningful interactions with the business leaders to develop the marketing plan that students will present to them.

This is consistent with Barr and McNeilly (2002) who assert that one critical value students gain from having meaningful, real-world experiences that contribute to their learning is to fully understand the job-related skills that are important to be effective in one's career. Meaningful experiential learning assignments help students build the skills necessary to demonstrate their job competence and to make wellthought-out decisions about their career options. When gathering data from recruiters who interview on college campuses to identify students who fit their open job postings, Barr and McNeilly (2002) found that $40 \%$ of the time, the recruiters asked about the specific classroom experiences the students had in their classes. Thus, using the process discussed in this paper gives students classroom experiences and assignments to discuss in job interviews that reflect real business activities. Students can discuss their knowledge with recruiters and provide strong evidence of business-relevant experiences that can translate directly to job performance.

\section{Student Feedback on this Learning Design}

In the spring of 2009, an online survey was completed by all students in the marketing classes. The questions gathered data on the students' perceptions of their learning experiences. When students were asked about the most satisfactory aspects of the course, their comments indicated that in many cases students had strong positive feelings about their project experience, and they commented directly about how it helped them to gain the necessary knowledge in the discipline. The following are examples of comments that addressed what contributed most to their learning:

Realistic study by using real case! The last presentation was so exciting because the professor used a project that made the important factors concepts clear and improved our knowledge of marketing.

The group projects were the best aspect of the course. Challenging at times but the connection with classmates and understanding the concepts was exceptional.

...To cooperate with selected company leaders to give students real experience is a very good technique. I can't think of anything else to improve this class. We had a great amount of project and hands-on experience.

There was also negative feedback from some of the students. This included the amount of work and time this type of project demanded from them. Students indicated that while they learned a lot through a real-life project, they do not see

InSight: A J ournal of Scholarly Teaching 
themselves taking more than one course that used the consulting project learning approach in the same semester.

From the perspective of learning the concepts presented in the class and applying them in a real-world context, it was clear that through this process the students were able to provide the business executives with valuable insights. The executives who participated, demonstrated enthusiasm and excitement to be part of the process and were able to make immediate changes based on students' recommendations.

We were honored to be considered as part of this important class project, thrilled throughout the entire process, and applaud the concept of using 'everyday businesses' in real-life situations as an instructional road map.

During the presentations the leaders described their experience. We flew down to participate in a 'mock-board meeting' where four groups presented their proposals about how our company could and should expand its current customer base to show added profits.

Upon returning to the office, we immediately applied a number of ideas brought forth by the students and witnessed increased earnings of approximately 27 percent in the first year. Obviously, solid instruction, coupled with real-world marketing approaches proved beneficial for our business, as well as for each of the students who worked on this for us.

These reflections suggest that both the student and the business have gained from this experience. In the design phase of this approach, we had doubts and concerns about the actual impact that students would be able to make over the course of one semester in one class. Now, we can share with our colleagues in business and other disciplines that this type of real-life consulting project can be an excellent way to engage both the students in our classes and the communities that we serve as part of an institution of higher education.

\section{Conclusion}

The concept of integrating client-based projects is not new and has been adopted by many (Lopez \& Lee, 2005; Li, Greenberg, \& Nicholls, 2007; Barr \& McNeilly, 2002). Existing research has addressed the benefits of this type of experiential learning in class, in which it provides a more stimulating educational experience (Li, Greenberg, \& Nicholls, 2007), helps to generate interest in course concepts (Lopez \& Lee, 2005), fosters a sense of students' ownership of the learning process (Lopez \& Lee, 2005), increases students' learning and motivation, improves students'

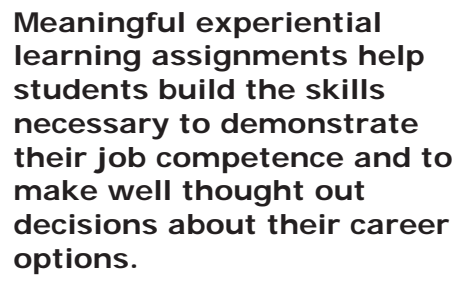

communication skills (Forman, 2006), and builds

students' career-relevant value and skills (Barr \& McNeilly, 2002). This pedagogy not only initiates a deeper level of understanding of course concepts but also facilitates a higher level of active learning.

While textbook principles provide a useful fundamental framework, student learning is enhanced when instructors integrate challenging organizational problems into assignments that give students opportunities to see the market by "being in the shoes of the executive" who is accountable for the success of the business. Learning is maximized when students step outside of the classroom through engaging in opportunities to work directly with people who face challenges and issues related to the concepts they are studying. Through this direct experience, students are able to 
develop the necessary skills to make informed decisions and to integrate textbook knowledge to address the complex issues which leaders face.

Furthermore, students who have an opportunity to have meaningful interactions with organizational leaders will expand their ability to retain the information learned in class as well as increase their self-confidence and knowledge about how to address complex marketing issues and opportunities in the real world. Learning about themselves, through the interactions with peers in class and executives outside of class, will provide students with a wider range of options regarding what they can personally do to increase their own professional impact. Students will receive valuable knowledge about how they can expand their own natural talents when working with organizational leaders, as well as identify what they need to improve or change in order to enhance their impact when working with and influencing others. Having deep learning experiences like the one described in this paper will help contribute to students' individual effectiveness and motivation.

\section{References}

Barr, T. F., \& McNeilly, K. M. (2002). The value of students' classroom experiences from the eyes of the recruiter: Information, implications, and recommendations for marketing educators. Journal of Marketing Education, 24(2), 168-173.

Daly, S. (2001). Student-operated Internet businesses: True experiential learning in entrepreneurship and retail management. Journal of Marketing Education, 23(3), 204-215.

Dewey, J. (1938). Education and experience. New York, NY: Simon \& Schuster.

Forman, H. (2006). Participative case studies: Integrating case writing and a traditional case study approach in a marketing context. J ournal of

Marketing Education, 28(2), 106-113.
Kolb, A. Y., \& Kolb, D. A. (2005). Learning styles and learning spaces: Enhancing experiential learning in higher education. Academy of Management Learning and Education, 4(2), 193-212.

Kolb, D. A. (1984). Experiential learning: Experience as the source of learning and development. New Jersey: Prentice-Hall.

Li, T., Greenberg, B. A., \& Nicholls, J. A. F. (2007). Teaching experiential learning: Adoption of an innovative course in an MBA marketing curriculum. Journal of Marketing Education, 29(1), 25-33.

Lopez, T. B., \& Lee, R. G. (2005). Five principles for workable clientbased projects: Lessons from the trenches. J ournal of Marketing Education, 27(2), 172-188.

Jeanny Liu is an Associate Professor of marketing at the University of La Verne. She completed her doctoral research and received her $\mathrm{PhD}$ in marketing at the University of Turin, Italy. Her research areas are consumer behavior and interactive marketing. She currently teaches marketing management and international marketing to undergraduate and MBA students. She is actively involved in course redesign to integrate experiential learning components to business courses at both undergraduate and graduate level.

Deborah Olson completed her masters and $\mathrm{PhD}$ in organizational psychology at Wayne State University. Dr. Olson is an Associate Professor of management at the University of La Verne. She teaches classes in management and leadership for both graduate and undergraduate students. She has worked on course redesign to incorporate media and experiential learning in class assignments and led international travel study classes for both graduate and undergraduate students. 